\title{
Wandering out of the GWAS wilderness: a new pathway paradigm for complex disease genetics
}

\author{
Jeffrey Sturek, Imre Noth
}

A genetic contribution to asthma susceptibility has long been recognised. ${ }^{1}$ Despite multiple approaches, from candidate genes to genome-wide association studies (GWAS), a large proportion of this heritability remains unexplained. ${ }^{2}$ The reasons for this are myriad and are largely generalisable to similar approaches in other complex diseases and phenotypes. Candidate gene studies are well based in known pathophysiology and can be powered to identify small effect sizes, but often provide limited insight into new biology or therapeutic opportunities. GWAS are largely unbiased (tagging single-nucleotide polymorphism (SNP) selection not withstanding) and provide opportunities for discovery, but identifying the biologically functional variant can prove daunting, and other important variants likely do not survive genome-wide significance corrections where sample sizes, and hence statistical power, are limited. Both of these approaches in isolation are also likely to miss the influence of genetics on the complex phenotypic response to environmental exposures. In this issue of Thorax, Dizier et al report an interesting pathway-based approach to a gene by environment $(\mathrm{G} \times \mathrm{E})$ analysis of a well-established epidemiological association between environmental tobacco smoke (ETS) exposure and bronchial hyper-responsiveness (BHR). ${ }^{3}$ This hybrid method has some of the benefits of multiple modalities and may provide a new avenue for further clarifying the genetic underpinnings of other complex diseases.

The basis for the current study comes from a preceding positional cloning study of the $17 \mathrm{p} 11$ region in the French Epidemiological study on the Genetics and Environment of Asthma (EGEA) families. This showed an interactive effect between ETS exposure and a variant in Dynein, Axonemal, Heavy Chain 9 (DNAH9) on BHR. $^{4} 5$ The DNAH9 gene encodes a

Division of Pulmonary and Critical Care, Department of Medicine, University of Virginia School of Medicine, Charlottesville, Virginia, USA

Correspondence to Dr Imre Noth, Division of Pulmonary and Critical Care, Department of Medicine, University of Virginia School of Medicine, Charlottesville, VA 22908, USA; IN2C@hscmail.mcc.virginia.edu subunit of axonemal dynein, a cytoskeletal motor protein critical for ciliary motility. Importantly, this subunit contains the components necessary for ATP binding and hydrolysis needed for conversion of stored chemical energy into mechanical work. ${ }^{6}$ Dizier et al reasoned that variants in other genes encoding for proteins with either ATP binding or ATPase functions might have similar interactions with ETS in BHR. This rationale was further supported by studies showing (1) a linkage between airway extracellular ATP and asthmatic inflammation ${ }^{7}$ and (2) reduced ATPase activity with cigarette smoke exposure. ${ }^{8}$

To test the hypothesis that genes belonging to 'ATPase activity' and 'ATP-binding' pathways interact with exposure to ETS in BHR, the authors first tested for this interaction with 4252 SNPs within all 296 genes in these pathways. Selected SNPs were restricted to within gene boundaries to limit the number of tests and to maintain power for interaction testing. This analysis was done in a discovery cohort of 388 French EGEA families using the Family-Based Association Test (FBAT) approach and yielded a significant SNP $\times$ ETS interaction for 20 SNPs from 11 different genes. ${ }^{9}$ These 20 SNPs were then tested for replication in 253 French-Canadian multigenerational families from the Saguenay-Lac-SaintJean (SLSJ) asthma study ${ }^{10}$ and again in a combined analysis of the two cohorts. Importantly, the definitions of the clinical measures (BHR and ETS) were highly consistent between the discovery and replication cohorts. Two SNP $\times$ ETS interactions were replicated between these analyses: rs2253304, an intronic SNP in ABCA1, and rs17448506, an intronic SNP in ATP8A1. The authors also validated the findings from the FBAT approach with a second method-the Umbach and Weinberg method. Interestingly, these two genes, ABCA1 and ATP8A1, are both involved in membrane lipid regulation. Additionally, both SNPs showed variable association with BHR based on exposure, a so-called 'flip-flop' interaction where the same allele was positively associated with BHR in ETS-exposed siblings and negatively associated with BHR in
ETS-unexposed siblings. Functionally, both SNPs map to enhancer and promoter histone marks and transcription factor binding sites, providing opportunities for altered regulation of expression. Finally, a review of curated data from the Comparative Toxicogenomics Database revealed that tobacco smoke pollution and soot have been shown to alter ATP8A1 and ABCA1 mRNA expression levels.

There are data to support a cellular mechanism for interaction between variants in membrane lipid regulatory genes and ETS in BHR. The ATP8A1 gene encodes for a transmembrane protein which is thought to maintain phospholipid asymmetry in membranes. Little is known about its functional role in the lung, though its expression does appear to be dynamically regulated, for example, by cigarette smoke. Knowledge of the role of ABCA1, however (along with ABCG1 and $\mathrm{ABCA} 3$ ) in lung biology is growing. ${ }^{11}$ ABCA1 is a transmembrane protein which mediates the efflux of cholesterol and phospholipids to the extracellular acceptor apolipoprotein A-I (apoA-I) in the process of reverse cholesterol transport. Mice deficient in ABCA1 develop significant pulmonary lipid accumulation. ${ }^{12} \mathrm{~A}$ number of studies suggest that this process may be important in pulmonary inflammation and asthma. In a study of patients with atopic and non-atopic asthma, serum high-density lipoprotein and apoA-I levels were positively correlated with $\mathrm{FEV}_{1}$ in subjects with atopy and asthma. ${ }^{13}$ ApoA-I levels have also been found to be lower in bronchoalveolar lavage samples from asthmatic patients as compared with healthy controls, and intranasal delivery of apoA-I decreased inflammation in house dust mite challenged mice. ${ }^{14}$ Likewise, overexpression of ABCA1 reduced inflammation in ovalbumin-challenged mice. ${ }^{15}$

So how might the identified variants in ABCA1 and ATP8A1 differentially modulate the effect of ETS exposure on BHR? And what might account for the 'flip-flop' interaction observed? One explanation might be that ABCA1 and ATP8A1 play different roles in airway homeostasis in healthy versus disease states. Alternatively, ETS exposure may differentially modulate ABCA1 and ATP8A1 expression through effects on transcriptional regulatory machinery active at the sites of the interacting SNPs. Future mechanistic studies may focus on the relative expression and function of ABCA1 and ATP8A1 in patients of differing genotypes, with and without ETS exposure. When able, the focus should be on disease-relevant tissues, such as alveolar macrophages or airway smooth muscle. 
The pathway-based $\mathrm{G} \times \mathrm{E}$ interaction testing employed by Dizier et al combines the pathophysiological foundation of a hypothesis-driven approach with the breadth of a hypothesis-generating one to allow for discovery of novel genetic bases for complex diseases. In the end, this revealed a novel pair of genes involved in membrane lipid regulation, providing support for further studies of pulmonary lipid homeostasis in asthma. Following this pathway-based $\mathrm{G} \times \mathrm{E}$ interaction approach in other complex diseases may yield similar promising avenues for future investigation.

Funding The authors have not declared a specific grant for this research from any funding agency in the public, commercial or not-for-profit sectors.

Competing interests None declared.

Patient consent for publication Not required.

Provenance and peer review Commissioned; externally peer reviewed.

(c) Author(s) (or their employer(s)) 2019. No commercial re-use. See rights and permissions. Published by BMJ.

\section{Check for updates}

To cite Sturek J, Noth I. Thorax 2019;74:215-216.

Accepted 2 January 2019

Published Online First 19 January 2019

\section{CLinked}

http://dx.doi.org/10.1136/thoraxjnl-2018-211797

Thorax 2019;74:215-216.

doi:10.1136/thoraxjnl-2018-212511

\section{REFERENCES}

1 Ober C, Hoffjan S. Asthma genetics 2006: the long and winding road to gene discovery. Genes Immun 2006; 7:95-100.

2 Wjst M, Sargurupremraj M, Arnold M. Genome-wide association studies in asthma: what they really told us about pathogenesis. Curr Opin Allergy Clin Immunol 2013:13:112-8

3 Dizier MH, Margaritte-Jeannin P, Pain L, et al. Interactive effect between ATPase-related genes and early-life tobacco smoke exposure on bronchial hyperresponsiveness detected in asthma-ascertained families. Thorax 2019;74:254-60.

4 Dizier MH, Bouzigon E, Guilloud-Bataille M, et al. Evidence for gene $x$ smoking exposure interactions in a genome-wide linkage screen of asthma and bronchial hyper-responsiveness in EGEA families. Eur I Hum Genet 2007;15:810-5.

5 Dizier MH, Nadif R, Margaritte-Jeannin P, et al. Interaction between the DNAH9 gene and early smoke exposure in bronchial hyperresponsiveness. Eur Respir J 2016:47:1072-81.

6 Roberts AJ, Kon T, Knight PJ, et al. Functions and mechanics of dynein motor proteins. Nat Rev Mol Cell Biol 2013;14:713-26.
7 Idzko M, Hammad H, van Nimwegen M, et al. Extracellular ATP triggers and maintains asthmatic airway inflammation by activating dendritic cells. Nat Med 2007:13:913-9.

8 Huynh TP, Mah V, Sampson VB, et al. Na, K-ATPase is a target of cigarette smoke and reduced expression predicts poor patient outcome of smokers with lung cancer. Am J Physiol Lung Cell Mol Physiol 2012;302:L1150-8.

9 Kauffmann F, Dizier MH, Pin I, et al. Epidemiological study of the genetics and environment of asthma, bronchial hyperresponsiveness, and atopy: phenotype issues. Am J Respir Crit Care Med 1997;156(Pt 2):S123-9.

10 Laprise C. The Saguenay-Lac-Saint-Jean asthma familial collection: the genetics of asthma in a young founder population. Genes Immun 2014;15:247-55.

11 Chai $A B$, Ammit AJ, Gelissen IC. Examining the role of $A B C$ lipid transporters in pulmonary lipid homeostasis and inflammation. Respir Res 2017;18:41.

12 Bates SR, Tao JQ, Collins HL, et al. Pulmonary abnormalities due to $A B C A 1$ deficiency in mice. $A m J$ Physiol Lung Cell Mol Physiol 2005;289:L980-L989.

13 Barochia AV, Kaler M, Cuento RA, et al. Serum apolipoprotein A-I and large high-density lipoprotein particles are positively correlated with FEV1 in atopic asthma. Am J Respir Crit Care Med 2015;191:990-1000.

14 Park SW, Lee EH, Lee EJ, et al. Apolipoprotein A potentiates lipoxin A4 synthesis and recovery of allergen-induced disrupted tight junctions in the airway epithelium. Clin Exp Allergy 2013;43:914-27.

15 Dai C, Yao X, Vaisman B, et al. ATP-binding cassette transporter 1 attenuates ovalbumin-induced neutrophilic airway inflammation. Am J Respir Cell Mol Biol 2014;51:626-36. 